\title{
Energy Transfer in Single Hydrogen-Bonded Water Molecules
}

\author{
Huib J. Bakker, ${ }^{*}$ Joop J. Gilijamse, and Anjan J. Lock ${ }^{[a]}$
}

We study the structure and dynamics of hydrogen-bonded complexes of $\mathrm{H}_{2} \mathrm{O} / \mathrm{HDO}$ and acetone dissolved in carbon tetrachloride by probing the response of the $\mathrm{O}-\mathrm{H}$ stretching vibrations with linear mid-infrared spectroscopy and femtosecond mid-infrared pump-probe spectroscopy. We find that the hydrogen bonds in these complexes break and reform with a characteristic time scale of $\approx 1$ ps. These hydrogen-bond dynamics are observed to play an important role in the equilibration of vibrational energy over the two $\mathrm{O}-\mathrm{H}$ groups of the $\mathrm{H}_{2} \mathrm{O}$ molecule. For both $\mathrm{H}_{2} \mathrm{O}$ and $\mathrm{HDO}$, the $\mathrm{O}-\mathrm{H}$ stretching vibrational excitation relaxes with a time constant of $6.3 \pm 0.3 \mathrm{ps}$, and the molecular reorientation has a time constant of $6 \pm 1 \mathrm{ps}$.

\section{Introduction}

The structure and dynamics of liquid water are extremely complicated, despite the relatively simple chemical structure of the water molecule. This complexity results from the fact that each water molecule can form up to four hydrogen bonds with other water molecules, leading to the formation of extended and complicated hydrogen-bonded networks. The dynamics of these networks form the basis of many of the anomalous properties of liquid water, such as its negative volume of melting, its density maximum at $4{ }^{\circ} \mathrm{C}$, and its extremely high melting and boiling temperatures. ${ }^{[1,2]}$

The hydrogen-bonded networks of liquid water consist of a large number of conjugated $\mathrm{O}-\mathrm{H} \cdots \mathrm{O}$.O systems. The effect of this conjugation on the strength of the hydrogen-bond interaction can be investigated by studying the vibrational spectrum of extremely small volumes of water. These small volumes of water can be realized in the form of inverse micelles: small droplets of water covered by a surfactant and contained in an apolar solvent matrix. ${ }^{[3]}$ As the size of the micelle decreases, the frequency of the $\mathrm{O}-\mathrm{H}$ stretching vibration increases, which shows that the hydrogen-bond interaction becomes weaker when the hydrogen-bonded network is truncated. ${ }^{[5,6]}$ Because confinement influences the strength of the hydrogen-bond interactions, it will also affect the dynamics and the relative arrangement of the water molecules, that is, the local structure of the liquid. This is an important notion, considering the fact that the structure and function of large (bio)molecules are often determined by water molecules that are confined in one or more dimensions ${ }^{[7-11]}$

Recently, the dynamics of water interacting with biomolecules were studied by comparing the spectral dynamics of a chromophore dissolved in bulk liquid water with those of the same chromophore embedded in a hydrated biomolecule. ${ }^{[12]}$ These spectral dynamics reflect the collective rearrangement of the water near the chromophore, and were found to be much slower within the hydrated (bio)molecule than in bulk water. This indicates that water molecules interacting with large biomolecular structures show slower orientational dynamics than the molecules in bulk liquid water. The spectral dynamics of a chromophore are mainly determined by surface layers of water, that is, by water that is confined in only one dimension. For water molecules that are completely surrounded by other molecules or molecular groups, that is, that are confined in three dimensions, the effect of confinement is expected to be even stronger.

Herein, we report on the properties of strongly confined water molecules. The systems studied consist of single water molecules that are hydrogen bonded to acetone. These hydrogen-bonded complexes are dissolved in an apolar solvent (carbon tetrachloride), and constitute the limiting case of an inverse micelle in which the micelle contains only a single water molecule. We found that these confined water molecules show energy transfer and relaxation dynamics that strongly differ from the corresponding dynamics of the molecules in bulk liquid water.

\section{Experimental Section}

We prepared hydrogen-bonded complexes of water and acetone molecules by dissolving water in a mixture of acetone and $\mathrm{CCl}_{4}$. In this solution, structures were formed in which a single water molecule is hydrogen-bonded with its $\mathrm{O}-\mathrm{H}$ groups to the $\mathrm{C}=\mathrm{O}$ groups of surrounding acetone molecules. The methyl groups of these acetone molecules have a favorable interaction with the apolar $\mathrm{CCl}_{4}$ solvent molecules, thus allowing the hydrogen-bonded complexes to enter the apolar solvent. We varied the concentration of water and acetone and found that the maximum concentration ratio of water to acetone is $1: 10$. Hence, the solution always contained an excess concentration of acetone. We observed the same dynamics at all concentrations, which shows that the formed hydrogen-bonded complexes of water and acetone do not depend on the concentration. The results presented here were obtained for a solution of $0.4 \mathrm{M}$ water and $4.0 \mathrm{M}$ acetone in $\mathrm{CCl}_{4}$. The molecular ratio of $\mathrm{H}_{2} \mathrm{O}$, acetone, and $\mathrm{CCl}_{4}$ was 1:10:40. The hydrogenbonded systems of $\mathrm{HDO}$ and acetone molecules were prepared by using a mixture of $\mathrm{H}_{2} \mathrm{O}$ and $\mathrm{D}_{2} \mathrm{O}$ instead of pure $\mathrm{H}_{2} \mathrm{O}$. The molecu-

[a] Prof. H. J. Bakker, J. J. Gilijamse, Dr. A. J. Lock

FOM Institute for Atomic and Molecular Physics

Kruislaan 407, 1098 SJ Amsterdam (The Netherlands)

E-mail:bakker@amolf.nl 
lar ratio of the resulting system of $\mathrm{HDO}, \mathrm{D}_{2} \mathrm{O}$, acetone, and $\mathrm{CCl}_{4}$ was 1:4:50:200. The structure and dynamics of the hydrogenbonded complexes were studied using linear mid-infrared spectroscopy and femtosecond mid-infrared pump-probe spectroscopy. ${ }^{[13-19]}$ In both techniques, the system was studied via the response of the $\mathrm{O}-\mathrm{H}$ stretching vibrations of the $\mathrm{H}_{2} \mathrm{O} / \mathrm{HDO}$ molecule. The linear absorption spectra were measured using a Perkin-Elmer spectrometer.

In the pump-probe experiments, an intense femtosecond midinfrared pulse (pump) was used to excite a fraction of the water molecules to the first excited vibrational state of the $\mathrm{O}-\mathrm{H}$ stretching vibration. The absorption changes that result from this excitation were probed with a second, much weaker pulse (probe). The probe pulse was sent through a variable delay to measure the time-dependence of these absorption changes. In the experiments on vibrational relaxation, the probe polarization was at the magic angle $\left(54.7^{\circ}\right)$ with respect to the polarization of the pump. In the experiments on the orientational relaxation, the probe was polarized at $45^{\circ}$ with respect to the direction of polarization of the pump, and was split after the sample into a parallel and a perpendicular part. The transmitted probe beams were dispersed by a monochromator, and detected by a $3 \times 32 \mathrm{MCT}$ (mercury-cadmium-telluride) array detector. The frequency resolution was $16 \mathrm{~cm}^{-1}$ per pixel of the array.

By measuring the absorption changes with probe pulses having polarizations parallel $\left(\Delta \alpha_{\|}\right)$and perpendicular $\left(\Delta \alpha_{\perp}\right)$ to the polarization of the pump, we determined the dynamics of the anisotropy of the excitation. The excitation was initially anisotropic, because predominantly $\mathrm{O}-\mathrm{H}$ groups that were oriented parallel to the pump polarization were excited. The anisotropy is defined by Equation (1):

$R=\frac{\Delta \alpha_{\|}-\Delta \alpha_{\perp}}{\Delta \alpha_{\|}+2 \Delta \alpha_{\perp}}$

For an ensemble of randomly oriented dipolar oscillators, $\Delta \alpha_{\|}=$ $3 \Delta \alpha \perp$ at zero delay, so that $R=0.4$. At later delays, $R$ decays because of the reorientation of the water molecule and/or because of energy transfer between the two O- $\mathrm{H}$ groups of the $\mathrm{H}_{2} \mathrm{O}$ molecule.

The femtosecond mid-infrared pulses used in the pump-probe experiments were generated via frequency-conversion processes that were pumped by the pulses of a commercial system of a Ti:Sapphire oscillator (SpectraPhysics), a regenerative amplifier, and a multipass amplifier (Quantronix). These pulses have a central wavelength of $800 \mathrm{~nm}$, a pulse energy of $2.6 \mathrm{~mJ}$, and a pulse duration of $100 \mathrm{fs}$. The mid-infrared pump pulses were generated via parametric generation and amplification in BBO and KTP crystals. The probe pulses were generated via parametric generation and amplification in a BBO crystal, followed by difference frequency generation in an $\mathrm{AgGaS}_{2}$ crystal. The pump and probe pulses were independently tunable between 2.6 and $3.3 \mu \mathrm{m}\left(3000-3800 \mathrm{~cm}^{-1}\right)$. The energies of the pump and probe pulse were 10 and $0.1 \mu \mathrm{J}$, respectively, and their respective spectral widths were $75 \mathrm{~cm}^{-1}$ and $300 \mathrm{~cm}^{-1}$ (full width at half maximum, FWHM). From frequency-resolved cross-correlation measurements, it follows that the large bandwidth of the probe pulse is not the result of a linear chirp.

\section{Results}

\subsection{Linear Absorption Spectra}

In Figure 1, linear absorption spectra are shown for the solution of $\mathrm{H}_{2} \mathrm{O}$, acetone, and $\mathrm{CCl}_{4}$ (solid curve), and for the solution of $\mathrm{HDO}, \mathrm{D}_{2} \mathrm{O}$, acetone, and $\mathrm{CCl}_{4}$ (dashed curve). Both spec-



b)

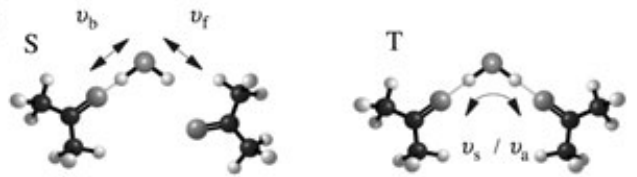

Figure 1. a) Spectra of $\mathrm{H}_{2} \mathrm{O}$ and $\mathrm{HDO}$ dissolved in a mixture of acetone and carbon tetrachloride. b) Also shown are schematic pictures of the two conformations $S$ and $T$ of the hydrogen-bonded water-acetone complex. The labels $v_{\mathrm{b}}$ and $v_{\mathrm{f}}$ denote the stretching vibrations of the hydrogen-bonded and the non-hydrogen-bonded $\mathrm{O}-\mathrm{H}$ group of structure $\mathrm{S}$, respectively. The labels $v_{\mathrm{s}}$ and $v_{\mathrm{a}}$ denote the symmetric and asymmetric stretching vibrations of the two hydrogen-bonded $\mathrm{O}-\mathrm{H}$ groups of structure T. The peak at $3400 \mathrm{~cm}^{-1}$ represents the absorption of the overtone of the $\mathrm{C}=\mathrm{O}$ stretching vibration of acetone.

tra contain a strong broad band at $3530 \mathrm{~cm}^{-1}$ and a weak narrow band at $3690 \mathrm{~cm}^{-1}$. These frequencies were obtained from a decomposition of the spectrum into Gaussian bands. The bands at $3530 \mathrm{~cm}^{-1}$ and $3690 \mathrm{~cm}^{-1}$ cannot be assigned to the symmetric and asymmetric $\mathrm{O}-\mathrm{H}$ stretching modes of $\mathrm{H}_{2} \mathrm{O}$, because they were also observed for the solution containing $\mathrm{HDO}$. Because of the similarity of the spectra of the systems containing $\mathrm{H}_{2} \mathrm{O}$ and $\mathrm{HDO}$, we assign the band at $3530 \mathrm{~cm}^{-1}$ to an $\mathrm{O}-\mathrm{H}$ group that is hydrogen bonded to a $\mathrm{C}=\mathrm{O}$ group of an acetone molecule $\left(v_{\mathrm{b}}\right)$, and the band at $3690 \mathrm{~cm}^{-1}$ to an $\mathrm{O}-\mathrm{H}$ group that is not hydrogen bonded $\left(v_{\mathrm{f}}\right) .^{[20,21]}$ Hence, in the dominant conformation formed by $\mathrm{H}_{2} \mathrm{O} / \mathrm{HDO}$ with acetone (structure $\mathrm{S}$ in Figure 1), only one of the two O-H/O-D groups of the $\mathrm{H}_{2} \mathrm{O} / \mathrm{HDO}$ molecule is hydrogen bonded to an acetone molecule. Owing to this hydrogen bond, the two $\mathrm{O}-\mathrm{H}$ vibrations are tuned out of resonance and no longer form mixed symmetric and asymmetric combination modes. The absorption of the band at $v_{\mathrm{b}}$ is much stronger than the band at $v_{\mathrm{f}}$ because the cross-section of the $\mathrm{O}-\mathrm{H}$ stretching vibration increases upon hydrogen-bond formation. 
The spectrum of the solution containing $\mathrm{H}_{2} \mathrm{O}$ shows a weak additional band at $3610 \mathrm{~cm}^{-1}$ that is not observed for HDO. This band indicates the presence of a less abundant second conformation (structure $\mathrm{T}$ in Figure 1), in which the water molecule forms two hydrogen bonds of about equal strength with two acetone molecules. As a result, the $\mathrm{O}-\mathrm{H}$ stretching vibrations of $\mathrm{H}_{2} \mathrm{O}$ form delocalized symmetric and antisymmetric vibrations. The antisymmetric $\mathrm{O}-\mathrm{H}$ stretching vibration is the band at $3610 \mathrm{~cm}^{-1}\left(v_{\mathrm{a}}\right)$. The symmetric $\mathrm{O}-\mathrm{H}$ stretching vibration has a weaker absorption than the antisymmetric $\mathrm{O}-\mathrm{H}$ stretching vibration and absorbs at a lower frequency. The absorption of this vibration cannot be discerned in the spectrum, likely because it is completely dominated by the strong $v_{\mathrm{b}}$ band of structure $S$.

The frequency of the asymmetric $\mathrm{O}-\mathrm{H}$ stretching vibration of $3610 \mathrm{~cm}^{-1}$ indicates that the frequency of the uncoupled hydrogen-bonded $\mathrm{O}-\mathrm{H}$ stretching vibration in structure $\mathrm{T}$ is approximately $3560 \mathrm{~cm}^{-1}$, because the frequency splitting of the symmetric and asymmetric $\mathrm{O}-\mathrm{H}$ stretching vibration of $\mathrm{H}_{2} \mathrm{O}$ is $\approx 100 \mathrm{~cm}^{-1}$. 22$]$ This means that hydrogen bond formation leads to a smaller red-shift of the $\mathrm{O}-\mathrm{H}$ stretching frequency in structure $T$ than in structure $S$, which shows that the hydrogen bonds of structure $T$ must be weaker than the single hydrogen bond of structure $\mathrm{S}$. This difference in hydrogenbond strength can be explained by steric effects. The formation of structure $T$ requires the proximity of two acetone molecules. Because the methyl groups of the acetone molecules repel each other, the hydrogen bonds to the water molecule remain relatively long and weak, making structure $T$ less stable and less abundant than structure $\mathrm{S}$.

\subsection{Femtosecond Pump-Probe Measurements}

In Figure 2, three transient spectra are shown at early delays after predominant excitation of either the $v_{\mathrm{b}}$, the $v_{\mathrm{a}}$ or the $v_{\mathrm{f}}$ mode of $\mathrm{H}_{2} \mathrm{O}$ hydrogen bonded to acetone. Figure 2 also shows decompositions of the spectra into increased transmissions and induced absorptions associated with the $v_{\mathrm{b}}, v_{\mathrm{a}}$, and $v_{\mathrm{f}}$ modes. In all spectra, there was an increased transmission of the three bands at $v_{\mathrm{b}}, v_{\mathrm{a}}$, and $v_{\mathrm{f}}$, which resulted from the bleaching of the fundamental $\mathrm{O} \rightarrow 1$ transition of the $\mathrm{O}-\mathrm{H}$ stretching vibrations. In addition, induced absorptions were observed at $3180,3350 \mathrm{~cm}^{-1}$, and $3570 \mathrm{~cm}^{-1}$. The broad band at $3350 \mathrm{~cm}^{-1}$ represents the $1 \rightarrow 2$ excited state absorption of both the $v_{\mathrm{b}}$ and $v_{\mathrm{a}}$ modes. This band is red-shifted compared to the fundamental transitions because of the anharmonicity of the $\mathrm{O}-\mathrm{H}$ stretching vibrations. The band at $3180 \mathrm{~cm}^{-1}$ is much weaker than the band at $3350 \mathrm{~cm}^{-1}$, and was only observed for the solution containing $\mathrm{H}_{2} \mathrm{O}$. Hence, this band likely results from the transition from the $v=1$ state of the $v_{\mathrm{f}}$ mode to the $v=2$ state of the $v_{\mathrm{b}}$ mode of the $\mathrm{H}_{2} \mathrm{O}$ molecule, which is a transition that involves a change of three vibrational quanta. The presence of this transition shows that the two $\mathrm{O}-\mathrm{H}$ groups of the $\mathrm{H}_{2} \mathrm{O}$ are strongly (anharmonically) coupled. The induced absorption at $3570 \mathrm{~cm}^{-1}$ is only clearly observed at early delays after pumping of the $v_{\mathrm{f}}$ mode (Figure $2 \mathrm{c}$ ). Therefore, we assign this band to the $1 \rightarrow 2$ excited state absorption
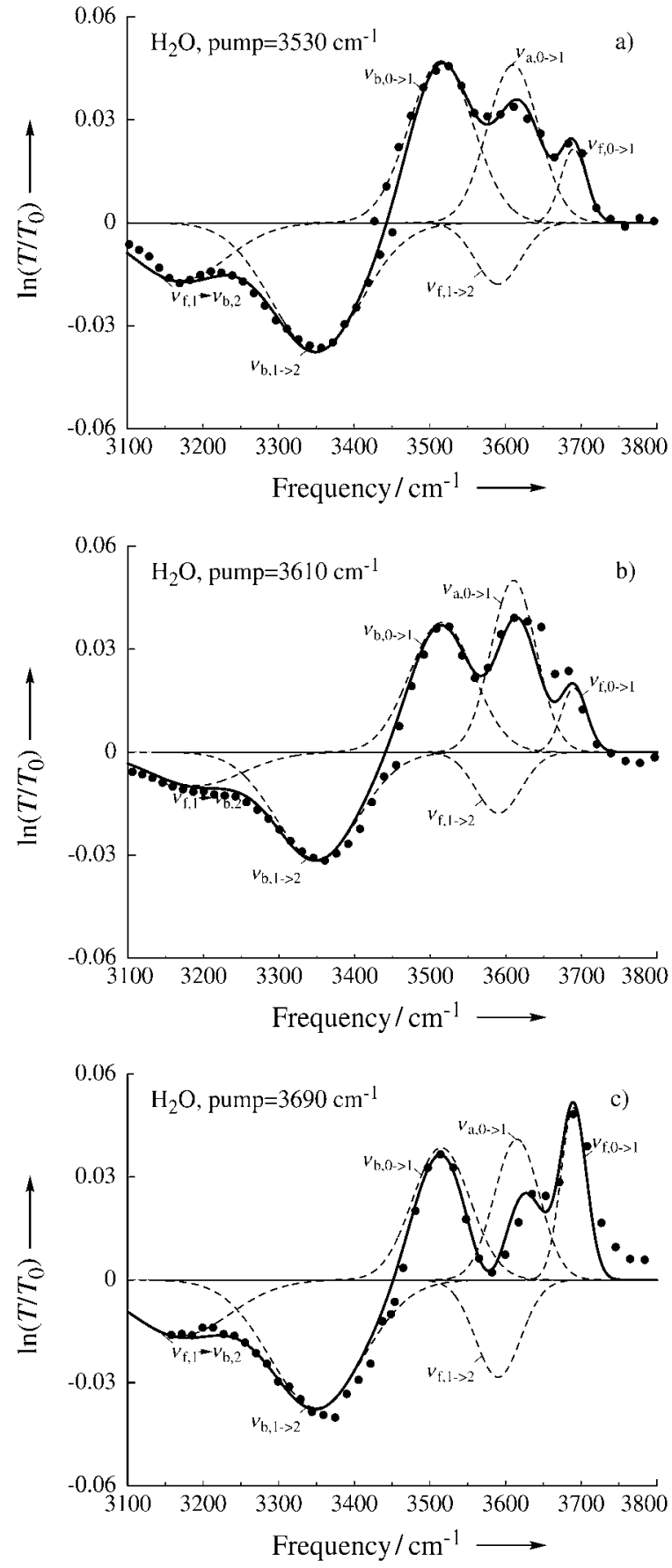

Figure 2. Transient spectra of complexes of $\mathrm{H}_{2} \mathrm{O}$ hydrogen bonded to acetone dissolved in $\mathrm{CCl}_{4}$ measured with three different pump frequencies. The pump frequencies lead to preferred excitation of the $v_{\mathrm{b}}$ mode $\left(3530 \mathrm{~cm}^{-1}\right)$, the $v_{\mathrm{a}}$ mode $\left(3610 \mathrm{~cm}^{-1}\right)$, and the $v_{\mathrm{f}}$ mode $\left(3690 \mathrm{~cm}^{-1}\right)$. The spectra are decomposed into six spectral components. The central frequencies, widths, and cross-sections of these spectral components are listed in Table 1. All curves result from a fit of the measurements to the kinetic model described in the text.

of this mode. When the $v_{\mathrm{b}}$ and $v_{\mathrm{a}}$ bands were predominantly excited (Figures $2 \mathrm{a}$ and $2 \mathrm{~b}$ ), the band at $3570 \mathrm{~cm}^{-1}$ is dominated by the bleaching signals of the $0 \rightarrow 1$ transitions of the $v_{\mathrm{b}}$ and $v_{\text {a }}$ modes.

In Figure 3, transient spectra are shown at three different delays after excitation of the $v_{\mathrm{b}}, v_{\mathrm{a}}$ and $v_{\mathrm{f}}$ modes. At early 



Figure 3. Transient spectra of complexes of $\mathrm{H}_{2} \mathrm{O}$ hydrogen bonded to acetone dissolved in $\mathrm{CCl}_{4}$ measured with the same pump frequencies as in Figure 2. Spectra are shown at three different delays, illustrating the equilibration between the $v_{\mathrm{b}}, v_{\mathrm{a}}$, and $v_{\mathrm{f}}$ modes and the vibrational relaxation. All curves result from a fit of the measurements to the kinetic model described in the text.

delays, all transient spectra show a strong bleaching signal of the band that was predominantly excited. In the first few picoseconds after the excitation, the pumped band shows a rapid decay. The bleaching bands corresponding to the other two modes decay more slowly (Figures $3 a$ and $3 b$ ), or even show an in-growth (Figure $3 \mathrm{c}$ ). These results indicate that the excita- tion of the initially excited $\mathrm{O}-\mathrm{H}$ band is transferred to the other two bands, leading to an equilibration of the excitation over the $v_{\mathrm{b}}, v_{\mathrm{a}}$ and $v_{\mathrm{f}}$ modes. For delays $>3 \mathrm{ps}$, the shapes of the transient spectra no longer change, and only the amplitudes of the spectra decrease as a result of vibrational relaxation.

When the $v_{\mathrm{b}}$ band was pumped (Figure $3 \mathrm{a}$ ), the signals measured at frequencies corresponding to the $v_{\mathrm{a}}$ and $v_{\mathrm{f}}$ modes did not show an in-growth. This is because these modes are superposed on the high-frequency wing of the strong, broad $v_{\mathrm{b}}$ band. The signals measured at frequencies corresponding to the $v_{\mathrm{a}}$ and $v_{\mathrm{f}}$ modes thus not only represent the in-growth of these modes due to energy transfer, but also the decay of the wing of the $v_{b}$ mode. The net effect is that the signals at frequencies corresponding to the $v_{\mathrm{a}}$ and $v_{\mathrm{f}}$ modes show a decay at all time delays, although the initial decay is much slower than the decay at frequencies corresponding to the pumped $v_{\mathrm{b}}$ mode.

To study the dynamics of the energy transfer and the vibrational relaxation in more detail, we measured the signal as a function of the time delay between the pump and probe pulses. In Figure $4 a$, the signal measured for the hydrogenbonded complex containing HDO at a probing frequency of $3530 \mathrm{~cm}^{-1}$ (corresponding to the maximum of $v_{\mathrm{b}}$ ) is shown. In the first three picoseconds, the dynamics show an additional fast decay when the $v_{\mathrm{b}}$ band is pumped, and a fast in-growth when the $v_{\mathrm{f}}$ band is pumped. These dynamics result from the equilibration of the excitation over the $v_{\mathrm{f}}$ and $v_{\mathrm{b}}$ bands. In Figure $4 \mathrm{~b}$, results are shown measured at the same pump and probe frequencies as in Figure $4 \mathrm{a}$, but now for the hydrogenbonded complex containing $\mathrm{H}_{2} \mathrm{O}$. The observed dynamics are the same as observed for the solution containing HDO. The results shown in Figure $4 \mathrm{c}$ were obtained by pumping the $v_{\mathrm{a}}$ band of the hydrogen-bonded complex containing $\mathrm{H}_{2} \mathrm{O}$. If the $v_{\mathrm{a}}$ band was also probed, the signal contained a rapid additional decay. If the $v_{\mathrm{b}}$ band was probed, a rapid in-growth was observed. This additional decay and in-growth were faster than the additional decay and in-growth observed in Figures $4 \mathrm{a}$ and $4 \mathrm{~b}$, which implies that the equilibration between $v_{\mathrm{b}}$ and $v_{\mathrm{a}}$ is faster than the equilibration between $v_{\mathrm{b}}$ and $v_{\mathrm{f}}$. After the equilibration, which is complete after $\approx 3 \mathrm{ps}$, all signals of Figure 4 show the same decay with a time constant of $6.3 \pm$ $0.3 \mathrm{ps}$. This time constant represents the averaged lifetime $T_{1}$ of the excitation of the $v=1$ state of the $v_{\mathrm{b}}, v_{\mathrm{a}}$ and $v_{\mathrm{f}}$ modes.

To obtain more insight into the mechanism of the energy transfer, we measured the anisotropy decay of the vibrational excitation. In Figure 5, the anisotropy is shown as a function of delay after excitation of the $v_{\mathrm{b}}$ mode. For the hydrogenbonded complex containing HDO, the anisotropy showed a single exponential decay with a time constant of $6 \pm 1$ ps (Figure $5 \mathrm{a}$ ). For the hydrogen-bonded complex containing $\mathrm{H}_{2} \mathrm{O}$, the dynamics of the decay strongly depended on the probe frequency (Figure $5 \mathrm{~b}$ ). If the probe frequency was resonant with the $v_{\mathrm{b}}$ mode, the signal showed a biexponential decay. The time constant of the first component is very similar to the time constant of the initial decay and in-growth observed in Figures $4 \mathrm{a}$ and $4 \mathrm{~b}$. The time constant of the second compo- 

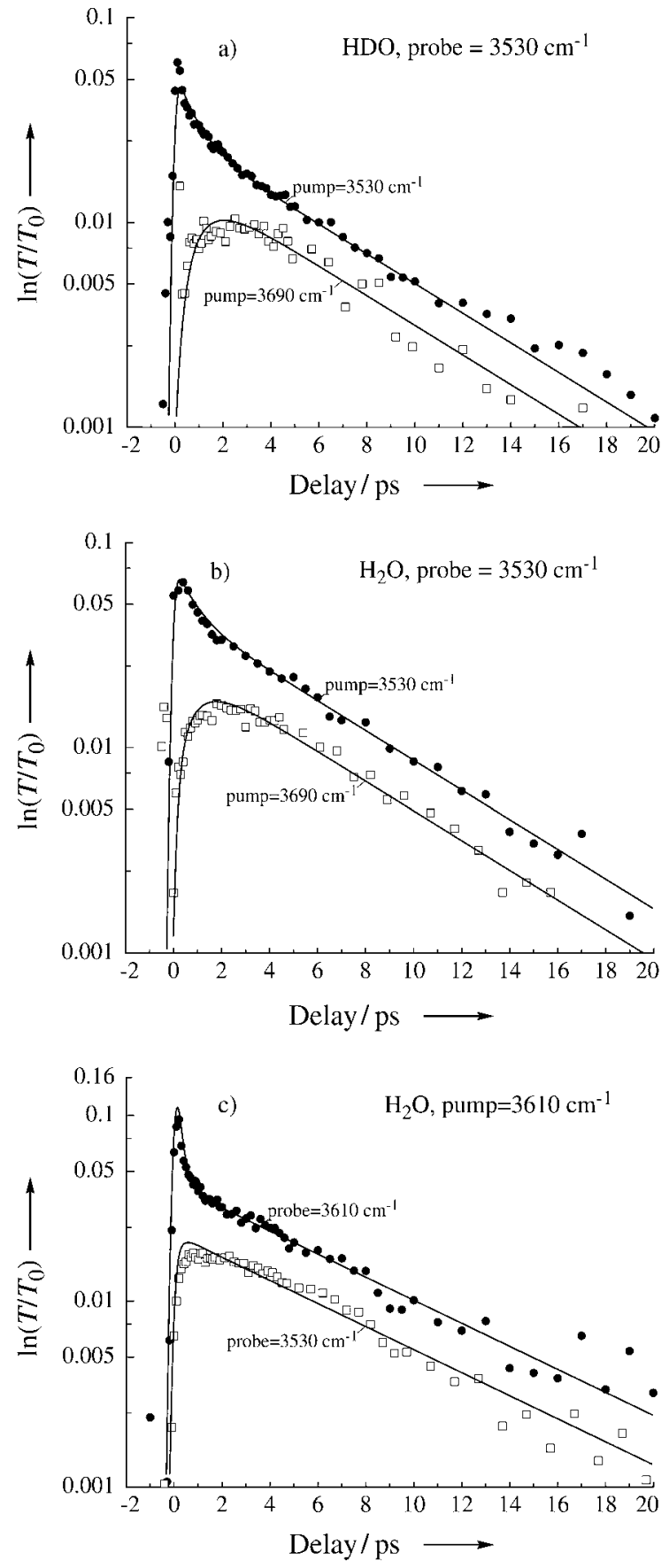

Figure 4. Delay time scans of complexes of $\mathrm{HDO}(\mathrm{a})$ and $\mathrm{H}_{2} \mathrm{O}(\mathrm{b}, \mathrm{c})$ hydrogen bonded to acetone dissolved in $\mathrm{CCl}_{4}$. $\mathrm{a}$,b) The probe frequency was $3530 \mathrm{~cm}^{-1}$, corresponding to the $v_{\mathrm{b}}$ mode, and the pump frequency was either $3530 \mathrm{~cm}^{-1}(\bullet)$ or $3690 \mathrm{~cm}^{-1}(\square)$, corresponding to the $v_{\mathrm{f}}$ mode. c) The pump frequency was $3610 \mathrm{~cm}^{-1}$, corresponding to the $v_{\mathrm{a}}$ mode, and the probe frequencies were either $3610 \mathrm{~cm}^{-1}(\bullet)$ or $3530 \mathrm{~cm}^{-1}(\square)$. All curves result from a fit of the data to the kinetic model described in the text.

nent is very similar to the time constant of the anisotropy decay of the hydrogen-bonded complex containing $\mathrm{HDO}: \mathrm{D}_{2} \mathrm{O}$. If the anisotropy was probed at a frequency that is resonant with the $v_{\mathrm{a}}$ mode, only the second component was observed, and the anisotropy starts at a value of $\approx 0.12$.
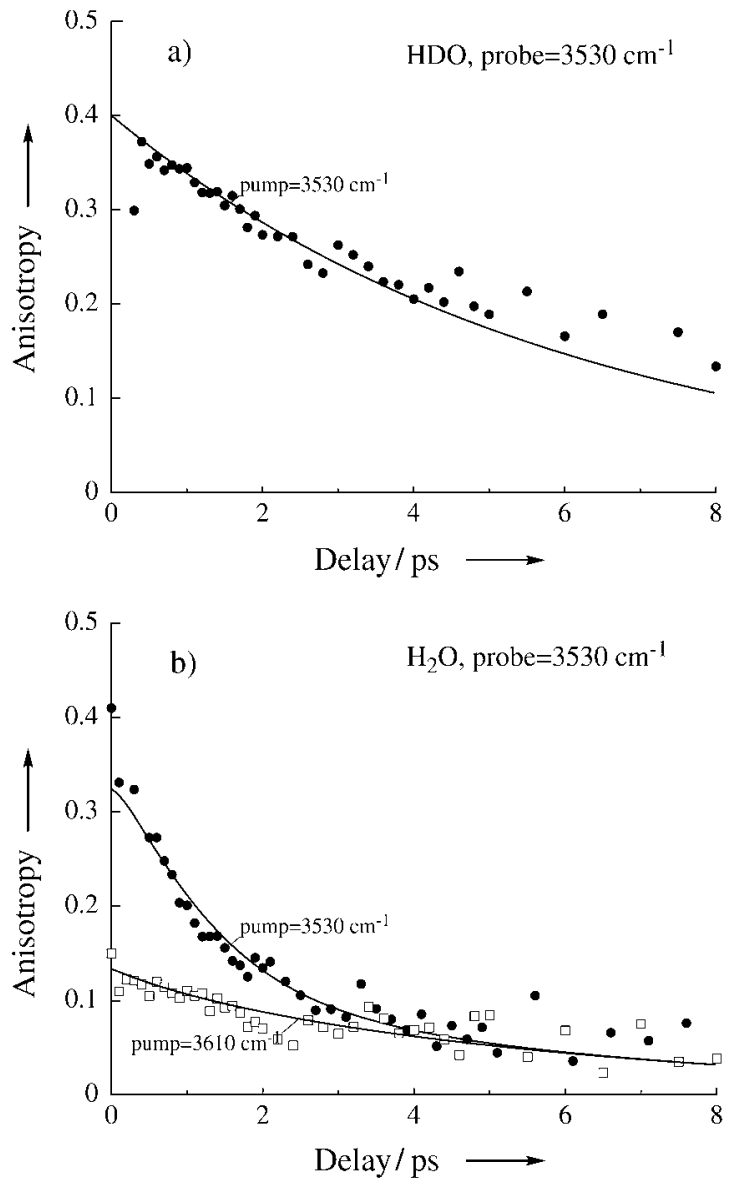

Figure 5. Anisotropy decay of complexes of $\mathrm{HDO}$ (a) and $\mathrm{H}_{2} \mathrm{O}(\mathrm{b})$ molecules hydrogen bonded to acetone dissolved in $\mathrm{CCl}_{4}$. a) The pump and probe frequencies were both $3530 \mathrm{~cm}^{-1}$, corresponding to the $v_{\mathrm{b}}$ mode. b) The probe frequency was $3530 \mathrm{~cm}^{-1}$ and the pump frequency was either $3530 \mathrm{~cm}^{-1}$ (৫) or $3610 \mathrm{~cm}^{-1}(\square)$, corresponding to the $v_{\mathrm{a}}$ mode. All curves result from a fit of the data to the kinetic model described in the text.

\section{Interpretation}

From the results of the previous section, it follows that both for $\mathrm{H}_{2} \mathrm{O}$ and $\mathrm{HDO}$ the $v_{\mathrm{b}}, v_{\mathrm{f}}$, and $v_{\mathrm{a}}$ modes show a rapid energy equilibration that is complete within three picoseconds. For $\mathrm{HDO}$, there is only one $\mathrm{O}-\mathrm{H}$ vibration that in structure $\mathrm{S}$ has to be either $a v_{\mathrm{b}}$ or $a v_{\mathrm{f}}$ mode. Hence, for HDO the transfer between $v_{\mathrm{b}}$ and $v_{\mathrm{f}}$ has to result from the interconversion between a structure $\mathrm{S}_{1}$ in which the $\mathrm{O}-\mathrm{H}$ group is hydrogen bonded and the $\mathrm{O}-\mathrm{D}$ group is non-hydrogen-bonded, to a structure $\mathrm{S}_{\|}$in which the $\mathrm{O}-\mathrm{H}$ group is non-hydrogen-bonded and the O-D group is hydrogen bonded.

Interestingly, the rate of energy transfer between $v_{\mathrm{b}}$ and $v_{\mathrm{f}}$ is the same for $\mathrm{H}_{2} \mathrm{O}$ as for HDO. This is unexpected, because for $\mathrm{H}_{2} \mathrm{O}$ the equilibration of $v_{\mathrm{b}}$ and $v_{\mathrm{f}}$ can in principle also result from an energy transfer between the hydrogen-bonded $\mathrm{O}-\mathrm{H}$ and the non-hydrogen-bonded $\mathrm{O}-\mathrm{H}$ group, without changing the hydrogen-bond interaction. Apparently, this direct transfer is very slow and does not contribute to the equilibration of the excitation over $v_{\mathrm{b}}$ and $v_{\mathrm{f}}$. This finding is surprising because it follows, from the presence of the $v_{\mathrm{f}}=1 \rightarrow v_{\mathrm{b}}=2$ transition at 
$3180 \mathrm{~cm}^{-1}$, that the two $\mathrm{O}-\mathrm{H}$ groups are strongly (anharmonically) coupled. This coupling does not lead to energy transfer between the two $\mathrm{O}-\mathrm{H}$ groups, most likely because the $\mathrm{O}-\mathrm{H}$ stretching vibrations are not sufficiently coupled to low-frequency solvent modes to enable a compensation of the energy mismatch of $\approx 160 \mathrm{~cm}^{-1}$ between the $v=1$ states of the $v_{\mathrm{b}}$ and $v_{\mathrm{f}}$ modes.

Although there is no direct energy transfer between the two $\mathrm{O}-\mathrm{H}$ groups of $\mathrm{H}_{2} \mathrm{O}$ within a particular hydrogen-bonded $\mathrm{S}$ structure, the anisotropy measurements of Figure $5 \mathrm{~b}$ show that such an energy transfer can occur when the hydrogen-bond conformation changes. When the $v_{\mathrm{b}}$ band of $\mathrm{H}_{2} \mathrm{O}$ is both pumped and probed, the anisotropy shows a decay to a value of $\approx 0.12$, with the same dynamics as the transfer between $v_{\mathrm{b}}$ and $v_{\mathrm{f}}$ shown in Figures $4 \mathrm{a}, \mathrm{b}$. The value of the anisotropy of $\approx 0.12$ can be explained from the equilibration of the $\mathrm{O}-\mathrm{H}$ stretching excitation over the two $\mathrm{O}-\mathrm{H}$ groups. After equilibration, the anisotropy has a value of $\frac{1}{2}\left[\frac{2}{5}+{ }_{5}^{2} P_{2}(\cos \delta)\right],^{[23]}$ where $P_{2}$ is the second-order Legendre polynomial and $\delta$ is the angle between the two transition dipoles. For $\delta=104^{\circ}$, which is the angle between the two $\mathrm{O}-\mathrm{H}$ groups of the water molecule, this expression gives an anisotropy of 0.12 , which is in excellent agreement with the experimental observa-

tion. Hence, the conversion between different $S$ structures can not only lead to a change of the vibrational frequency of the excited $\mathrm{O}-\mathrm{H}$ group, but also to a transfer of energy between the two $\mathrm{O}-\mathrm{H}$ groups of the $\mathrm{H}_{2} \mathrm{O}$ molecule. The residual anisotropy of 0.12 decays with the same time constant that is observed for the anisotropy decay of the HDO molecule. Therefore, we assign this second component to the molecular reorientation of the $\mathrm{H}_{2} \mathrm{O} / \mathrm{HDO}$ molecule.

The results of Figures $4 \mathrm{c}$ and $5 \mathrm{~b}$ show that the energy transfer between the two $\mathrm{O}-\mathrm{H}$ groups of the $\mathrm{H}_{2} \mathrm{O}$ molecule proceeds through structure T. From the measurements of Figure $4 c$, it follows that structure $T$ is rapidly converted into $S$, and that during this conversion the excitation of the $v_{\mathrm{a}}$ mode is transferred to an excitation of the $v_{\mathrm{b}}$ mode. From Figure $5 \mathrm{~b}$, it follows that when the $v_{\mathrm{a}}$ band is pumped and the $v_{\mathrm{b}}$ band is probed, the anisotropy starts at a value of $\approx 0.12$, which implies that in the conversion from $\mathrm{T}$ to $\mathrm{S}$ the two $\mathrm{O}-\mathrm{H}$ groups of $\mathrm{H}_{2} \mathrm{O}$ have an equal probability of becoming the hydrogenbonded $\mathrm{O}-\mathrm{H}$ group, and acquiring the $v=1$ excitation of the $v_{\mathrm{b}}$ mode. Note that the anisotropy does not give information on the dynamics of the conversion between $T$ and $S$, because tion of that group is excited. the anisotropy parameter only reflects the orientation of the probed excitation, and not its amplitude. Hence, when the $v_{\mathrm{a}}$ band is pumped and the $v_{\mathrm{b}}$ band is probed, the anisotropy directly starts at a value of approximately 0.12 , despite the fact that at early time delays the amount of population transferred to the $v_{\mathrm{b}}$ band will be small.

On the basis of the above findings, we can identify the mechanism by which energy is transferred between the $v_{\mathrm{b}}, v_{\mathrm{f}}$ and $v_{\mathrm{a}}$ modes. This mechanism is shown in Figure 6. First, the

F. Schematic diagram of the mechanism of energy transfer between the two $\mathrm{O}-\mathrm{H}$ groups of an $\mathrm{H}_{2} \mathrm{O}$ molecule hydrogen bonded to acetone. The four structures, $\mathrm{S}_{\mathrm{IIV}}$ differ in which $\mathrm{O}-\mathrm{H}$ group is hydrogen bonded and in which local $\mathrm{O}-\mathrm{H}$ vibration $\left(v_{\mathrm{b}}\right.$ or $v_{\mathrm{f}}$ ) is excited. An arrow next to an $\mathrm{O}-\mathrm{H}$ group denotes that the stretching vibra-

hydrogen bond to one of the $\mathrm{O}-\mathrm{H}$ groups of an $\mathrm{S}$ structure weakens while simultaneously a new hydrogen bond is formed at the other $\mathrm{O}-\mathrm{H}$ group. When the hydrogen bonds are about equal in strength, the system has evolved from structure $S$ to structure $\mathrm{T}$. In structure $\mathrm{T}$, the $\mathrm{O}-\mathrm{H}$ stretching vibrations are in near resonance, leading to the conversion of the original local excitation of $v_{\mathrm{b}}$ or $v_{\mathrm{f}}$ to the delocalized excitation of $v_{\mathrm{s}}$ or $v_{\mathrm{a}}$. Structure $T$ is converted back into one of the four different structures $S_{I-I V}$ by strengthening one of the hydrogen bonds and breaking the other. In this process, the delocalized excitation of $v_{\mathrm{s}}$ or $v_{\mathrm{a}}$ changes into an excitation of $v_{\mathrm{b}}$ or $v_{\mathrm{f}}$ localized on one of the two $\mathrm{O}-\mathrm{H}$ groups.

For HDO, there are only two $\mathrm{S}$ structures, because the excitation of the $\mathrm{O}-\mathrm{H}$ stretching vibration can reside at only one side of the molecule. Therefore, for HDO, the $\mathrm{S}$ structures are either $\mathrm{S}_{\mid}$and $\mathrm{S}_{\| \mathrm{II}}\left(\mathrm{O}-\mathrm{H}\right.$ at the right side of the molecule), or $\mathrm{S}_{\| I}$ and $\mathrm{S}_{\mathrm{IV}}(\mathrm{O}-\mathrm{H}$ at the left side of the molecule). Hence, for HDO, the interconversion of the $\mathrm{S}$ and T structures leaves the excitation at the same side of the molecule. This process leads to an equilibration of the vibrational excitation over the $v_{\mathrm{b}}$ and $v_{\mathrm{f}}$ modes with the same time constant as is observed for $\mathrm{H}_{2} \mathrm{O}$. 
The conversion between structures $\mathrm{S}$ and $\mathrm{T}$ takes place on an ultrashort time scale of $\approx 1 \mathrm{ps}$, which implies that this conversion cannot involve diffusion of water and/or acetone molecules through the $\mathrm{CCl}_{4}$ solvent, because such a process would take place on a much longer time scale. On a picosecond time scale, there can only be minor translations and rotations of the molecules that result in a change of the length of the hydrogen bonds between the water and the acetone molecules. The conversion between $S$ and $T$ thus results from a slight relative repositioning of a water molecule and two acetone molecules, and does not directly involve the $\mathrm{CCl}_{4}$ solvent molecules.

\section{Kinetic Model}

The rate constants of the mechanism shown in Figure 6 can be obtained from a fit to the measurements of Figures 2, 3, 4, and 5. The populations of $\mathrm{S}_{\mathrm{IIV}}$ and $\mathrm{T}$ obey a set of rate equations that can be written in the matrix form of Equation (2):

$$
\frac{\mathrm{d}}{\mathrm{d} t}\left(\begin{array}{c}
S_{\mathrm{I}}(t) \\
S_{\mathrm{II}}(t) \\
S_{\mathrm{III}}(t) \\
S_{\mathrm{IV}}(t) \\
T(t)
\end{array}\right)=\left(\begin{array}{ccccc}
-k_{\mathrm{b} 1} & 0 & 0 & 0 & k_{\mathrm{th}} \\
0 & -k_{\mathrm{ft}} & 0 & 0 & k_{\mathrm{tf}} \\
0 & 0 & -k_{\mathrm{ft}} & 0 & k_{\mathrm{tf}} \\
0 & 0 & 0 & -k_{\mathrm{bt}} & k_{\mathrm{bb}} \\
k_{\mathrm{ht}} & k_{\mathrm{ft}} & k_{\mathrm{ft}} & k_{\mathrm{bt}} & -2\left(k_{\mathrm{bb}}+k_{\mathrm{lf}}\right)
\end{array}\right)\left(\begin{array}{c}
S_{\mathrm{I}}(t) \\
S_{\mathrm{II}}(t) \\
S_{\mathrm{III}}(t) \\
S_{\mathrm{IV}}(t) \\
T(t)
\end{array}\right)
$$

where $k_{\mathrm{bt}}$ is the rate constant for the transfer from structures $\mathrm{S}_{\mathrm{I}}$ and $\mathrm{S}_{\mathrm{IV}}$, with an excited $v_{\mathrm{b}}$ vibration to structure $\mathrm{T}$ with an excited $v_{\mathrm{s}} / v_{\mathrm{a}}$ vibration; $k_{\mathrm{tb}}$ is the rate constant for the transfer back from $T$ to $S_{1}$ and $S_{\mathrm{IV}} ; k_{\mathrm{ft}}$ is the rate constant for the transfer from structures $\mathrm{S}_{\| \mid}$and $\mathrm{S}_{\| I}$ with an excited $v_{\mathrm{f}}$ vibration to structure $\mathrm{T}$ with an excited $v_{\mathrm{s}} / v_{\mathrm{a}}$ vibration; and $k_{\mathrm{tf}}$ is the rate constant for the transfer back from $T$ to $S_{\|}$and $S_{\| I \mid}$. These equations can be solved by finding the eigenvalues and eigenvectors of the square matrix containing the rate constants. The five eigenvalues $\lambda_{1}, \lambda_{2}, \lambda_{3}, \lambda_{4}$, and $\lambda_{5}$ are given by Equations ( $3 \mathrm{a}-\mathrm{e}$ ):

$\lambda_{1}=0$

$\lambda_{2}=-k_{\mathrm{bt}}$

$\lambda_{3}=-k_{\mathrm{ft}}$

$\lambda_{4}=\frac{1}{2}\left\{-k_{\mathrm{bt}}-k_{\mathrm{ft}}-2 k_{\mathrm{tb}}-2 k_{\mathrm{tf}}\right.$

$\left.-\sqrt{\left(k_{\mathrm{bt}}+k_{\mathrm{ft}}+2 k_{\mathrm{tb}}+2 k_{\mathrm{tf}}\right)^{2}-4\left(k_{\mathrm{bt}} k_{\mathrm{ft}}+2 k_{\mathrm{ft}} k_{\mathrm{tb}}+2 k_{\mathrm{bt}} k_{\mathrm{tf}}\right)}\right\}$

$\lambda_{5}=\frac{1}{2}\left\{-k_{\mathrm{bt}}-k_{\mathrm{ft}}-2 k_{\mathrm{tb}}-2 k_{\mathrm{tf}}\right.$

$\left.+\sqrt{\left(k_{\mathrm{bt}}+k_{\mathrm{ft}}+2 k_{\mathrm{tb}}+2 k_{\mathrm{tf}}\right)^{2}-4\left(k_{\mathrm{bt}} k_{\mathrm{ft}}+2 k_{\mathrm{ft}} k_{\mathrm{tb}}+2 k_{\mathrm{bt}} k_{\mathrm{tf}}\right)}\right\}$

The corresponding eigenvectors can be written in matrix form, Equation (4):

$$
V=\left(\begin{array}{ccccc}
\frac{k_{\mathrm{bb}}}{N_{1} k_{\mathrm{bl}}} & \frac{k_{\mathrm{ff}}}{N_{1} k_{\mathrm{ft}}} & \frac{k_{\mathrm{tf}}}{N_{1} k_{\mathrm{ft}}} & \frac{k_{\mathrm{lb}}}{N_{1} k_{\mathrm{bl}}} & \frac{1}{N_{1}} \\
\frac{1}{\sqrt{2}} & 0 & 0 & \frac{-1}{\sqrt{2}} & 0 \\
0 & \frac{1}{\sqrt{2}} & \frac{-1}{\sqrt{2}} & 0 & 0 \\
\frac{k_{\mathrm{bb}}}{N_{4}\left(k_{\mathrm{b}}+\lambda_{4}\right)} & \frac{k_{\mathrm{ff}}}{N_{4}\left(k_{\mathrm{ft}}+\lambda_{4}\right)} & \frac{k_{\mathrm{tf}}}{N_{4}\left(k_{\mathrm{ft}}+\lambda_{4}\right)} & \frac{k_{\mathrm{lb}}}{N_{4}\left(k_{\mathrm{bl}}+\lambda_{4}\right)} & \frac{1}{N_{4}} \\
\frac{k_{\mathrm{tb}}}{N_{5}\left(k_{\mathrm{b}}+\lambda_{5}\right)} & \frac{k_{\mathrm{tf}}}{N_{5}\left(k_{\mathrm{ft}}+\lambda_{5}\right)} & \frac{k_{\mathrm{ff}}}{N_{5}\left(k_{\mathrm{ft}}+\lambda_{5}\right)} & \frac{k_{\mathrm{bb}}}{N_{5}\left(k_{\mathrm{bt}}+\lambda_{5}\right)} & \frac{1}{N_{5}}
\end{array}\right)
$$

where $N_{1}, N_{4}$, and $N_{5}$ denote normalization constants. When the populations $S_{\mathrm{I}}(t), S_{\|}(t), S_{\| \mid}(t), S_{\mathrm{IV}}(t)$, and $T(\mathrm{t})$ are transformed into $X_{1-5}(t)$ following the eigenvectors of Equation (4), the five differential equations of Expression(2) are decoupled and easily solved, Equation (5):

$X_{i}(t)=X_{i}(0) e^{\lambda_{i} t}$

The factors $X_{i}(0)$ are obtained from Equation (6):

$\left(\begin{array}{l}X_{1}(0) \\ X_{2}(0) \\ X_{3}(0) \\ X_{4}(0) \\ X_{5}(0)\end{array}\right)=V\left(\begin{array}{l}S_{I}(0) \\ S_{I I}(0) \\ S_{I I I}(0) \\ S_{I V}(0) \\ T(0)\end{array}\right)$

where $S_{\mid}(0), S_{\| \mid}(0), S_{\| I}(0), S_{I V}(0)$, and $T(0)$ are the populations generated by the pump-pulse excitation. The populations $S_{1}(t)$, $S_{\mathrm{II}}(t), S_{\mathrm{III}}(t), S_{\mathrm{IV}}(\mathrm{t})$, and $T(t)$ were obtained by multiplying $X(t)$ with the inverse matrix of the eigenvectors, Equation (7), which is the transpose of the matrix of Equation (4):

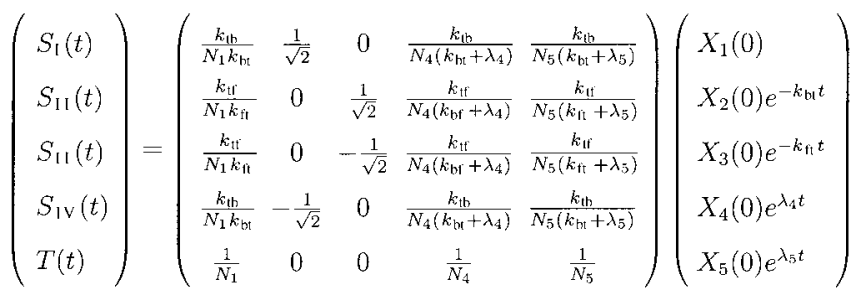

In the experiments, we did not measure the populations as a function of real time, but we measured the absorption changes of the probe as a function of the delay time $\tau$ between the pump and the probe pulses. These absorption changes not only reflect the dynamics of the populations, but can also contain contributions from spectral diffusion and coherent coupling effects. We did not observe any effect of spectral diffusion within each of the bands corresponding to the $0 \rightarrow 1$ transitions of the $v_{\mathrm{b}}, v_{\mathrm{a}}$, and $v_{\mathrm{f}}$ bands, because the bandwidth of the pump is comparable to the spectral widths of these bands. The coherent coupling of the pump and probe pulses will affect the pump-probe signal for time delays that are shorter than the durations of these pulses and that are shorter than the time constant of the dephasing. In the pres- 
ent experiments, the time constants of all dynamics are significantly longer than the pulse durations of the pump and probe and the time constant of the dephasing. Moreover, we found that the coherent coupling effects were small, probably because the probe pulse was not bandwidth limited. ${ }^{[24]}$ Hence, coherent coupling effects can be neglected in modeling the data, and the measured pump-probe signals can be assumed to reflect only the absorption changes associated with the delay-dependent populations of the different structures $S$ and T. The delay-dependent populations can then be obtained by convoluting the time-dependent populations with a Gaussian function representing the cross-correlation trace of the pump and probe pulses, Equation (8):

$S_{i}(\tau)=\int_{-\infty}^{\infty} \mathrm{d} t S_{i}(t) e^{-4 \ln 2(\tau-t)^{2} / \tau_{c c}^{2}}$

where $\tau_{\mathrm{cc}}$ is the FWHM of the cross-correlation trace.

To calculate the transient absorption spectra, the delay-dependent population changes $S_{\mid}(\tau), S_{||}(\tau), S_{|I|}(\tau), S_{\text {IV }}(\tau)$, and $T(\tau)$ have to be related to spectral changes. The transient spectra can be decomposed into seven bands. Three of these bands represent the absorptions $\alpha_{\mathrm{b} 0 \rightarrow \mathrm{b} 1}, \alpha_{\mathrm{a} 0 \rightarrow \mathrm{a} 1}$, and $\alpha_{\mathrm{f} 0 \rightarrow \mathrm{f} 1}$ of the fundamental $v=0 \rightarrow 1$ transitions of the $v_{\mathrm{b}}, v_{\mathrm{a}}$ and $v_{\mathrm{f}}$ modes, respectively. Three other bands are formed by the induced absorptions $\alpha_{\mathrm{b} 1 \rightarrow \mathrm{b} 2}, \alpha_{\mathrm{a} 1 \rightarrow \mathrm{a} 2}$, and $\alpha_{\mathrm{f} 1 \rightarrow \mathrm{f} 2}$ that correspond to the $v=$ $1 \rightarrow 2$ transitions of the $v_{\mathrm{b}}, v_{\mathrm{a}}$ and $v_{\mathrm{f}}$ modes, respectively. The seventh band represents the absorption $\alpha_{\mathrm{f} 1 \rightarrow \mathrm{b} 2}$ corresponding to the transition from the $v=1$ state of the $v_{\mathrm{f}}$ mode to the $v=$ 2 state of the $v_{\mathrm{b}}$ mode. The total time- and frequency-dependent absorption change $\Delta \alpha_{\text {tot }}(\omega, \tau)$ is given by Equation (9):

$$
\begin{aligned}
& \Delta \alpha_{\mathrm{tot}}(\omega, \tau)=\left[S_{\mathrm{I}}(\tau)+S_{\mathrm{IV}}(\tau)\right]\left[\alpha_{\mathrm{b} 1 \rightarrow \mathrm{b} 2}(\omega)-\alpha_{\mathrm{b} 0 \rightarrow \mathrm{b} 1}(\omega)\right] \\
& +\left[S_{\mathrm{II}}(\tau)+S_{\mathrm{III}}(\tau)\right]\left[\alpha_{\mathrm{f} 1 \rightarrow \mathrm{f} 2}(\omega)+\alpha_{\mathrm{f} 1 \rightarrow \mathrm{b} 2}(\omega)-\alpha_{\mathrm{f} 0 \rightarrow \mathrm{f} 1}(\omega)\right] \\
& +T(\tau)\left[\alpha_{\mathrm{a} 1 \rightarrow \mathrm{a} 2}(\omega)-\alpha_{\mathrm{a} 0 \rightarrow \mathrm{a} 1}(\omega)\right]
\end{aligned}
$$

The initial populations $S_{\text {I-IV }}$ and $T$ were determined by the linear spectrum and the pump spectrum. The shape of the (equilibrium) linear spectrum follows from the absorptions $\alpha_{\mathrm{b} 0 \rightarrow \mathrm{b} 1}, \alpha_{\mathrm{a} 0 \rightarrow \mathrm{a} 1}, \alpha_{\mathrm{f} 0 \rightarrow \mathrm{f} 1}$ and the rate constants $k_{\mathrm{bt}}, k_{\mathrm{ft}}, k_{\mathrm{tb}}, k_{\mathrm{tf}}$. The initial populations $S_{I}$ and $S_{\mathrm{IV}}$ are proportional to the spectral overlap of the pump with the $v_{b}$ band of the linear spectrum; the initial populations $S_{\|}$and $S_{\text {III }}$ to the overlap of the pump with the $v_{\mathrm{f}}$ band; and the initial population $T$ to the overlap of the pump with the $v_{\mathrm{a}}$ band.

In the calculation of the anisotropy, we assumed that initially only one of the populations $S_{\mathrm{I}}(\tau), S_{\mathrm{II}}(\tau), S_{\mathrm{III}}(\tau), S_{\mathrm{IV}}(\tau)$, or $T(\tau)$ was excited by the pump pulse. The anisotropy of the excitation can then be calculated by Equation (10):

$$
\begin{aligned}
& R(\omega, \tau)=A e^{-\tau / \tau_{\mathrm{or}}}+\frac{B}{\Delta \alpha_{\mathrm{tot}}(\omega \tau)}\left\{\left[S_{\mathrm{I}}(\tau)-S_{\mathrm{IV}}(\tau)\right]\left[\alpha_{\mathrm{b} 1 \rightarrow \mathrm{b} 2}(\omega)-\alpha_{\mathrm{b} 0 \rightarrow \mathrm{b} 1}(\omega)\right]\right. \\
& \left.+\left[S_{\mathrm{II}}(\tau)-S_{\mathrm{III}}(\tau)\right]\left[\alpha_{\mathrm{f} 1 \rightarrow \mathrm{f} 2}(\omega)+\alpha_{\mathrm{f} 1 \rightarrow \mathrm{b} 2}(\omega)-\alpha_{\mathrm{f} 0 \rightarrow \mathrm{f} 1}(\omega)\right]\right\}
\end{aligned}
$$

where $\tau_{\text {or }}$ is the molecular reorientation time. The coefficients $A$ and $B$ are determined by the angle between the two $\mathrm{O}-\mathrm{H}$ groups in the $\mathrm{H}_{2} \mathrm{O}$ molecule. Hence, $A=0.12$ and $B=0.28$.

For HDO, the dynamics will be somewhat different because the $\mathrm{O}-\mathrm{H}$ stretching excitation can reside at only one side of the molecule. However, this will neither affect the equilibration between $v_{\mathrm{f}}$ and $v_{\mathrm{b}}$, nor the equilibration between the $\mathrm{S}$ structures and T. The only dynamics that will not be present for $\mathrm{HDO}$ are the equilibration dynamics between $\mathrm{S}_{\mathrm{I}}$ and $\mathrm{S}_{\mathrm{IV}}$ and the equilibration dynamics between $S_{\|}$and $S_{\text {III. }}$. These dynamics only affect the decay of the anisotropy. Hence, the population dynamics of the hydrogen-bonded complexes containing HDO can be calculated with the same equations that are used for the complexes containing $\mathrm{H}_{2} \mathrm{O}$ if we take $\mathrm{S}_{\mathrm{I}}(\tau)+\mathrm{S}_{\mathrm{IV}}(\tau)$ as the population of the hydrogen-bonded $v_{\mathrm{b}}$ mode, and $S_{||}(\tau)+S_{\text {III }}(\tau)$ as the population of the non-hydrogen-bonded $v_{\mathrm{f}}$ mode. The anisotropy decay of HDO can be described by taking $A=0.4$ and $B=0$ in Equation (10).

The model described above was fitted to all transient spectra measured with different delays. The seven spectral components $\alpha_{\mathrm{b} 0 \rightarrow \mathrm{b} 1}, \alpha_{\mathrm{a} 0 \rightarrow \mathrm{a} 1}, \alpha_{\mathrm{f} 0 \rightarrow \mathrm{f} 1}, \alpha_{\mathrm{b} 1 \rightarrow \mathrm{b} 2}, \alpha_{\mathrm{a} 1 \rightarrow \mathrm{a} 2}, \alpha_{\mathrm{f} 1 \rightarrow \mathrm{f} 2}$, and $\alpha_{\mathrm{f} 1 \rightarrow \mathrm{b} 2}$ are all described as Gaussian functions: $\alpha=(\sigma / \Delta v) e^{-4 \ln 2\left(v-v_{0}\right)^{2} / \Delta v^{2}}$. Because we could not distinguish $\alpha_{\mathrm{a} 1 \rightarrow \mathrm{a} 2}$ from $\alpha_{\mathrm{b} 1 \rightarrow \mathrm{b} 2}$ in the transient spectra, we assumed these absorption changes to have the same spectral shape. The fit parameters are thus the central frequencies $v_{0}$, widths $\Delta v$, and cross-sections $\sigma$ of six spectral components, the rate constants $k_{\mathrm{bt}}, k_{\mathrm{ft}}, k_{\mathrm{tb}}, k_{\mathrm{t} f}$ and the time constants $T_{1}$ and $\tau_{\text {or }}$. The parameters resulting from the fits are listed in Tables 1 and 2.

\section{Discussion}

From Table 1, it follows that the cross-sections of the hydrogen-bonded $v_{\mathrm{b}}$ and $v_{\mathrm{a}}$ modes are larger than the cross-section of the non-hydrogen-bonded $v_{\mathrm{f}}$ mode. This agrees with the

Table 1. Central frequencies $v_{0}$, widths $\Delta v$ and cross-sections $\sigma$ of the seven spectral components used to fit the data of Figures $2-5$. The crosssections $\sigma$ are defined relative to that of the $0 \rightarrow 1$ transition of the $v_{\mathrm{b}}$ mode.

\begin{tabular}{|llll|} 
& $v_{0}\left[\mathrm{~cm}^{-1}\right]$ & $\Delta v\left[\mathrm{~cm}^{-1}\right]$ & $\sigma$ \\
\hline$\alpha_{\mathrm{b} 0 \rightarrow \mathrm{b} 1}$ & $3520 \pm 5$ & $90 \pm 5$ & 1 \\
$\alpha_{\mathrm{a} 0 \rightarrow \mathrm{a} 1}$ & $3610 \pm 10$ & $70 \pm 5$ & $1.09 \pm 0.05$ \\
$\alpha_{\mathrm{f} 0 \rightarrow \mathrm{f} 1}$ & $3690 \pm 5$ & $40 \pm 5$ & $0.36 \pm 0.05$ \\
$\alpha_{\mathrm{b} 1 \rightarrow \mathrm{b} 2}$ & $3350 \pm 10$ & $145 \pm 10$ & $1.13 \pm 0.05$ \\
$\alpha_{\mathrm{a} 1 \rightarrow \mathrm{a} 2}$ & $3350 \pm 10$ & $145 \pm 10$ & $1.13 \pm 0.05$ \\
$\alpha_{\mathrm{f} 1 \rightarrow \mathrm{f} 2}$ & $3570 \pm 15$ & $70 \pm 5$ & $0.35 \pm 0.10$ \\
$\alpha_{\mathrm{f} 1 \rightarrow \mathrm{b} 2}$ & $3170 \pm 10$ & $155 \pm 20$ & $0.48 \pm 0.10$ \\
\hline
\end{tabular}

Table 2. Rate constants and time constants $T_{1}$ and $\tau_{\text {or }}$ used to fit the data of Figures 2-5. $6 \pm 1$ ps 
notion that the cross-section of the $\mathrm{O}-\mathrm{H}$ stretching vibration increases with increasing hydrogen-bond interaction. ${ }^{[1]}$ Hence, it may be surprising that $\alpha_{\mathrm{a} 0 \rightarrow \mathrm{a} 1}$ is even somewhat larger than $\alpha_{\mathrm{b} 0 \rightarrow \mathrm{b} 1}$, because the two hydrogen bonds of the T structure are weaker than the hydrogen bond of the $S$ structure. However, the asymmetric $\mathrm{O}-\mathrm{H}$ stretching vibration $v_{\mathrm{a}}$ takes a larger part of the cross-sections of the constituting local $\mathrm{O}-\mathrm{H}$ stretching oscillators than the symmetric $v_{s}$ mode, because the angle between the two $\mathrm{O}-\mathrm{H}$ groups of $\mathrm{H}_{2} \mathrm{O}$ is larger than $90^{\circ}$.

The equilibrated population ratio of structures $S$ and $T$ is $\left(S_{1}+S_{\text {IV }}\right):\left(S_{\| 1}+S_{I I I}\right): T$ is $2 k_{\mathrm{tb}} / k_{\mathrm{bt}}: 2 k_{\mathrm{tf}} / k_{\mathrm{ft}}: 1$. With the time constants obtained from the fit, this ratio is $2.2: 1.6: 1$, meaning that structure $S$ is approximately four times more abundant than structure $T$. If the ratio of structures $S$ and $T$ were statistical, structure $\mathrm{S}$ would have been twice as abundant as structure $\mathrm{T}$, because there are two possible realizations for structure $S$ (the hydrogen bond of structure $S$ can be at the left or at the right $\mathrm{O}-\mathrm{H} / \mathrm{O}-\mathrm{D}$ group) and only one for structure $\mathrm{T}$. The four-fold higher relative abundance of $S$ structures implies that structure $T$ has a higher energy than the $S$ structures. Hence, the rate constants $k_{\mathrm{tb}}$ and $k_{\mathrm{tf}}$ are rate constants of downhill reactions, whereas $k_{\mathrm{bt}}$ and $k_{\mathrm{ft}}$ are rate constants of uphill reactions. Thus, when the energy barriers of the reactions are small, $k_{\mathrm{tb}}$ and $k_{\mathrm{tf}}$ are the same but $k_{\mathrm{bt}}$ and $k_{\mathrm{ft}}$ differ. The latter rate constants will depend on the energy difference with structure T. From the ratio of the rate constants, it follows that structure $T$ is $\approx 170 \mathrm{~cm}^{-1}$ higher in energy than structure $\mathrm{S}_{\mathrm{I}} / \mathrm{S}_{\mathrm{IV}}$, and $\approx 100 \mathrm{~cm}^{-1}$ higher in energy than structure $S_{\| \mid} / S_{\| 1}$. It should be realized that these values form averages over the energy differences in the $v=1$ and the $v=0$ states, because the rate constants are mainly derived from the bleaching signals that represent the dynamics in both the $v=1$ and the $v=0$ states. In $v=0$, the energy differences between structure $\mathrm{T}$ and the $\mathrm{S}$ structures are expected to be all the same, because in this state all $\mathrm{S}$ structures are equivalent. In $v=1$, the energy difference between $T$ and $S_{\mathrm{I}} / \mathrm{S}_{\mathrm{IV}}$ is expected to be $\approx 160 \mathrm{~cm}^{-1}$ larger than that between $T$ and $S_{\| \mid} / S_{\| I}$, because of the difference in excitation energy of the $v=1$ states of the $v_{\mathrm{b}}$ and $v_{\mathrm{f}}$ modes. From the excitation energies of the $v=1$ states of the $S$ and $T$ structures and the values of the average energy differences (averaged over $v=0$ and $v=1$ ), we estimate the energy differences to be $\approx 200 \mathrm{~cm}^{-1}$ between $\mathrm{T}$ and $\mathrm{S}_{\mathrm{I}} / \mathrm{S}_{\mathrm{IV}}$ in the $v=1$ state, $\approx 50 \mathrm{~cm}^{-1}$ between $\mathrm{T}$ and $\mathrm{S}_{||} / \mathrm{S}_{\| I}$ in the $v=1$ state, and $\approx 140 \mathrm{~cm}^{-1}$ between $T$ and $\mathrm{S}_{\mathrm{IIV}}$ in the $v=0$ state. From these energy differences, the time constants for the conversion are $k_{\mathrm{bt}, 1}^{-1} \approx 1.3 \mathrm{ps}, k_{\mathrm{ft}, 1}^{-1} \approx 0.65 \mathrm{ps}$, and $k_{\mathrm{bt}, 0}^{-1}=k_{\mathrm{ft}, 0}^{-1} \approx 0.95 \mathrm{ps}$, where the additional subscript denotes that the hydrogen-bonded complexes are in either the $v=1$ or the $v=0$ state. In this calculation, the time constants $k_{\mathrm{tb}, 1}^{-1}, k_{\mathrm{tf}, 1}^{-1}, k_{\mathrm{tb}, 0}^{-1}$ and $k_{\mathrm{tf}, 0}^{-1}$ for the conversion from $T$ to the different structures $S$ are assumed to be all equal to $0.5 \mathrm{ps}$, because they correspond to downhill reactions. From these time constants, it follows that the ratio $\left(S_{1}+\right.$ $\left.S_{\text {IV }}\right):\left(S_{||}+S_{\text {III }}\right): T$ is 2.6:1.3:1 in the $v=1$ state and 1.9:1.9:1 in the $v=0$ state.

From the values of $k_{\mathrm{bt}}, k_{\mathrm{ft}}, k_{\mathrm{tb}}$, and $k_{\mathrm{t} f}$, it follows that the individual hydrogen bonds of the water-acetone complexes change in strength with a time constant of approximately $1 \mathrm{ps}$.
This means that the hydrogen-bond dynamics of $\mathrm{H}_{2} \mathrm{O} / \mathrm{HDO}$ hydrogen bonded to acetone are somewhat slower than the hydrogen-bond dynamics of bulk liquid water. For bulk liquid water, the hydrogen-bond dynamics were observed to have two components of similar amplitude with time constants of $\approx 100 \mathrm{fs}$ and $\approx 1 \mathrm{ps}^{[25-27]}$ The slower hydrogen-bond dynamics of $\mathrm{H}_{2} \mathrm{O} / \mathrm{HDO}$ hydrogen bonded to acetone may be somewhat surprising, because the hydrogen bonds between $\mathrm{H}_{2} \mathrm{O} / \mathrm{HDO}$ and acetone have a smaller binding energy than the hydrogen bonds in bulk liquid water. However, in bulk liquid water, the local breaking of a hydrogen bond can be directly coupled to a strengthening of several other nearby hydrogen bonds. Hence, in bulk liquid water, the energy required for breaking a local hydrogen bond is lower than the binding energy of the hydrogen bond. For a $\mathrm{H}_{2} \mathrm{O} / \mathrm{HDO}$ molecule hydrogen bonded to acetone, a similar coordinated weakening of one hydrogen bond and strengthening of another hydrogen bond occurs in the transition between structures $S$ and $T$. However, because this transfer involves only two hydrogen bonds, the energy needed for this transfer is likely to be higher than the energy required for the breaking of a local hydrogen bond in bulk liquid water. An additional effect may be that the transfer between structures $S$ and $T$ involves the motion of acetone molecules that are much heavier than water molecules, which will slow down the hydrogen-bond dynamics.

The orientational relaxation time constant $\tau_{\text {or }}$ of $6 \pm 1 \mathrm{ps}$ of the $\mathrm{H}_{2} \mathrm{O} / \mathrm{HDO}$ molecule hydrogen bonded to acetone is significantly longer than the orientational relaxation time constant of 2.6 ps of $\mathrm{HDO}$ dissolved in $\mathrm{D}_{2} \mathrm{O} \cdot{ }^{[28]}$ For $\mathrm{HDO}$ dissolved in $\mathrm{D}_{2} \mathrm{O}$, it was found that orientational relaxation only occurs after significant weakening of the hydrogen-bond interaction. Hence, for this system, the rate of reorientation is determined by the time scale on which the strength of the hydrogen bond fluctuates, and the fraction of HDO molecules for which the hydrogen bond to the $\mathrm{O}-\mathrm{H}$ group is sufficiently weak to allow reorientation. If we assume that the $\mathrm{H}_{2} \mathrm{O} / \mathrm{HDO}$ molecule hydrogen bonded to acetone can only reorient as a result of the rotation of the non-hydrogen-bonded O-H/O-D groups of the S structures, we can estimate the reorientation time constant of these groups from their relative abundance. The relative abundance of non-hydrogen-bonded $\mathrm{O}-\mathrm{H} / \mathrm{O}-\mathrm{D}$ groups is given by $0.5 \times$ $\left(S_{1}+S_{I I}+S_{I I I}+S_{I V}\right):\left(S_{1}+S_{I I}+S_{I I I}+S_{I V}+T\right)$. Hence, the estimated reorientation time of the non-hydrogen-bonded $\mathrm{O}-\mathrm{H} / \mathrm{O}-\mathrm{D}$ group is $0.5(2.2+1.6) /(2.2+1.6+1) \times 6 \mathrm{ps}=2.4 \mathrm{ps}$. The time constant of $2.4 \mathrm{ps}$ for the reorientation of a non-hydrogenbonded $\mathrm{O}-\mathrm{H} / \mathrm{O}-\mathrm{D}$ group is surprisingly long. In comparison, the rotation of a free $\mathrm{O}-\mathrm{H} / \mathrm{O}-\mathrm{D}$ rotor takes place with a time constant of only $\approx 100 \mathrm{fs}$, and the non-hydrogen-bonded $\mathrm{O}$ $\mathrm{H} / \mathrm{OD}$ groups of $\mathrm{HDO}: \mathrm{D}_{2} \mathrm{O}$ have a reorientation time constant of $\approx 400 \mathrm{fs} .{ }^{[29]}$ Apparently, the non-hydrogen-bonded $\mathrm{O}-\mathrm{H} / \mathrm{O}-$ D groups of the $\mathrm{H}_{2} \mathrm{O} / \mathrm{HDO}$ molecule hydrogen bonded to acetone are strongly hindered in their reorientation, which shows that the water molecule is not only strongly confined in the directions along the $\mathrm{O}-\mathrm{H}$ groups, but also in the directions perpendicular to these groups.

The vibrational relaxation time constant $T_{1}$ of $6.3 \pm 0.3 \mathrm{ps}$ of the $\mathrm{H}_{2} \mathrm{O}$ and $\mathrm{HDO}$ molecule hydrogen bonded to acetone is 
much longer than the $T_{1}$ of liquid $\mathrm{H}_{2} \mathrm{O}^{[30-33]}$ and of HDO dissolved in $\mathrm{D}_{2} \mathrm{O} \cdot{ }^{[15,34]}$ This large difference in $T_{1}$ can be explained by the difference in strength of the hydrogen-bond interaction. There are several mechanisms by which a weaker hydrogenbond interaction can lead to an increase in the vibrational lifetime. In the first place, a weaker hydrogen bond makes the frequency of the $\mathrm{O}-\mathrm{H}$ stretching vibration higher, and thus influences the energy difference between the $\mathrm{O}-\mathrm{H}$ stretching vibration and specific combination tones of accepting modes. For liquid $\mathrm{H}_{2} \mathrm{O}$, the increase in $T_{1}$ with temperature has been explained by a decrease in the spectral overlap of the $\mathrm{O}-\mathrm{H}$ stretching vibration absorption and the overtone of the bending mode. ${ }^{[31]}$ For $\mathrm{H}_{2} \mathrm{O} / \mathrm{HDO}$ hydrogen bonded to acetone, the frequency of the $\mathrm{O}-\mathrm{H}$ stretching vibrations is high in comparison with liquid $\mathrm{H}_{2} \mathrm{O}$. Hence, in principle, the long vibrational lifetime of $\mathrm{H}_{2} \mathrm{O} / \mathrm{HDO}$ hydrogen bonded to acetone could be explained from the poorer overlap with the overtone of the bending mode. However, the $T_{1}$ values of $\mathrm{H}_{2} \mathrm{O}$ and $\mathrm{HDO}$ hydrogen bonded to acetone are very similar, whereas their bending mode frequencies differ strongly. Therefore, it is unlikely that the long $T_{1}$ of $\mathrm{H}_{2} \mathrm{O} / \mathrm{HDO}$ hydrogen bonded to acetone results from a decreased spectral overlap with the overtone of the bending mode.

The strength of the hydrogen-bond interaction also determines the properties of intermolecular modes like the hydrogen-bond stretching vibrations and the librational modes. In liquid water, the hydrogen-bond stretching vibrations and the librational modes have relatively high frequencies of $\approx 200 \mathrm{~cm}^{-1}$ and $\approx 600 \mathrm{~cm}^{-1}$, respectively, ${ }^{[35]}$ and these modes are strongly coupled to the $\mathrm{O}-\mathrm{H}$ stretching vibration. For $\mathrm{H}_{2} \mathrm{O}$ / HDO hydrogen bonded to acetone, the frequencies of these modes are much lower and these modes are not as strongly coupled. Hence, if the hydrogen-bond stretching vibrations and/or the librational modes form accepting modes in the vibrational relaxation, the increase in $T_{1}$ going from liquid water to $\mathrm{H}_{2} \mathrm{O} / \mathrm{HDO}$ hydrogen bonded to acetone can be well explained from the weaker coupling to these modes. ${ }^{[36]}$ This explanation is also consistent with the observation that the value of $T_{1}$ is very similar for $\mathrm{H}_{2} \mathrm{O}$ and $\mathrm{HDO}$ hydrogen bonded to acetone, because the frequencies of the hydrogen-bond stretching vibrations and the librational modes are only weakly dependent on the isotopic composition of the water molecule.

\section{Conclusions}

We studied the structure and dynamics of hydrogen-bonded complexes of single $\mathrm{H}_{2} \mathrm{O} / \mathrm{HDO}$ molecules and acetone dissolved in $\mathrm{CCl}_{4}$ with linear vibrational spectroscopy and femtosecond mid-infrared pump-probe spectroscopy. We found that an $\mathrm{H}_{2} \mathrm{O} / \mathrm{HDO}$ molecule can form two different hydrogenbonded structures with acetone. In the dominant structure $\mathrm{S}$, only one of the O-H/O-D groups is hydrogen bonded to the $\mathrm{C}=\mathrm{O}$ group of an acetone molecule. In the less abundant structure $\mathrm{T}$, both $\mathrm{O}-\mathrm{H} / \mathrm{O}-\mathrm{D}$ groups are hydrogen bonded, but these hydrogen bonds are weaker than the single hydrogen bond of structure $\mathrm{S}$. Structure $\mathrm{S}$ has a vibrational mode $v_{\mathrm{b}}$ with a frequency of $3530 \mathrm{~cm}^{-1}$ located on the hydrogen-bonded $\mathrm{O}-\mathrm{H}$ group, and a vibrational mode $v_{\mathrm{f}}$ with a frequency of $3690 \mathrm{~cm}^{-1}$ located on the non-hydrogen-bonded $\mathrm{O}-\mathrm{H}$ group. In structure $\mathrm{T}$, the $\mathrm{H}_{2} \mathrm{O}$ molecule has delocalized $v_{\mathrm{s}}$ and $v_{\mathrm{a}} \mathrm{O}-\mathrm{H}$ stretching vibrational modes, of which only the latter is observed at a frequency of $3610 \mathrm{~cm}^{-1}$.

Femtosecond mid-infrared pump-probe experiments showed that the hydrogen bonds between the water and the acetone molecules change in strength with a time constant of $\approx 1 \mathrm{ps}$. These hydrogen-bond dynamics result in the interconversion of structures $\mathrm{S}$ and $\mathrm{T}$ and in the exchange of the excitation of the $\mathrm{O}-\mathrm{H}$ stretching vibration between the $v_{\mathrm{b}}, v_{\mathrm{a}}$, and $v_{\mathrm{f}}$ modes. The hydrogen-bond dynamics also result in the transfer of the vibrational excitation between the two $\mathrm{O}-\mathrm{H}$ groups of the $\mathrm{H}_{2} \mathrm{O}$ molecule via the mechanism that is depicted in Figure 6.

In this mechanism, the excitation of one of the $\mathrm{O}-\mathrm{H}$ groups of $\mathrm{H}_{2} \mathrm{O}$ in structure $\mathrm{S}\left(v_{\mathrm{b}}\right.$ or $\left.v_{\mathrm{f}}\right)$ first changes into a delocalized excitation of structure $\mathrm{T}\left(v_{\mathrm{s}}\right.$ or $\left.v_{\mathrm{a}}\right)$. When $\mathrm{T}$ is converted back to $\mathrm{S}$, the delocalized excitation changes back into a localized excitation of one of the $\mathrm{O}-\mathrm{H}$ groups $\left(v_{\mathrm{b}}\right.$ or $v_{\mathrm{f}}$ ). Hence, structure $\mathrm{T}$ forms the transition state for the energy transfer between the two $\mathrm{O}-\mathrm{H}$ groups of the $\mathrm{H}_{2} \mathrm{O}$ molecule. We found that there is no direct energy transfer between the two $\mathrm{O}-\mathrm{H}$ groups within a fixed structure $S$, probably because of the energy mismatch between the $v=1$ states of $v_{\mathrm{b}}$ and $v_{\mathrm{f}}$ of $\approx 160 \mathrm{~cm}^{-1}$.

From a kinetic modeling of the data, we found that the transfer from structure $\mathrm{S}$ to $\mathrm{T}$ is somewhat faster when the $v_{\mathrm{f}}$ vibration is excited $\left(k_{\mathrm{ft}}^{-1}=0.8 \pm 0.2 \mathrm{ps}\right)$ than when the $v_{\mathrm{b}}$ vibration is excited $\left(k_{\mathrm{bt}}^{-1}=1.1 \pm 0.2 \mathrm{ps}\right)$. This difference can be explained by the higher energy of the $v=1$ state of the $v_{\mathrm{f}}$ vibration. The equilibrated vibrational excitation decays with a time constant of $6.3 \pm 0.3 \mathrm{ps}$. This vibrational lifetime is the same for the $\mathrm{H}_{2} \mathrm{O}$ and the $\mathrm{HDO}$ molecule, which indicates that intermolecular modes like the hydrogen-bond stretching vibrations and the librational modes form accepting modes of the vibrational energy. The molecular reorientation has a time constant of $6 \pm 1 \mathrm{ps}$.

All dynamics (hydrogen bond, energy transfer, vibrational relaxation, molecular reorientation) of $\mathrm{H}_{2} \mathrm{O} / \mathrm{HDO}$ hydrogen bonded to acetone are much slower than the corresponding dynamics of bulk liquid water. This difference in dynamics can only be partly explained by the difference in strength of the hydrogen-bond interaction. The hydrogen bond between a water molecule and the $\mathrm{C}=\mathrm{O}$ group of acetone is somewhat weaker than the hydrogen bonds of bulk liquid water, from which it can be expected that the vibrational relaxation and energy transfer are slower, as is indeed observed, but also that the hydrogen-bond dynamics and the molecular reorientation are faster, which does not agree with the observations. The translational and rotational dynamics of the $\mathrm{H}_{2} \mathrm{O} / \mathrm{HDO}$ molecule thus turn out to be much more dependent on the local structure of the liquid and the nature of the surrounding molecules than on the strength of the local hydrogen-bond interactions. 


\section{Acknowledgements}

This work is part of the research program of the "Stichting voor Fundamenteel Onderzoek der Materie (FOM)", which is financially supported by the "Nederlandse organisatie voor Wetenschappelijk Onderzoek (NWO)".

Keywords: femtochemistry - hydrogen bonds - kinetics vibrational spectroscopy $\cdot$ water

[1] F. Franks, Water: A Comprehensive Treatise, Plenum Press, New York, 1972.

[2] D. Eisenberg, W. Kauzman, The Structure and Properties of Water, Oxford University Press, London, 1969.

[3] D. S. Venables, K. Huang, C. A. Schmuttenmaer, J. Phys. Chem. B 2001 105, 9132.

[4] G. Seifert, T. Patzla, H. Graener, Phys. Rev. Lett. 2002, 88, 147402.

[5] J.-B. Brubach, A. Mermet, A. Filabozzi, A. Gerschel, D. Lairez, M. P. Kraft, P. Roy, J. Phys. Chem. B 2001, 105, 43.

[6] M. Freda, G. Onori, A. Paciaroni, A. Santucci, J. Mol. Liq. 2002, 101, 55.

[7] W. A. P. Luck, Water and lons in Biological Systems, Plenum, New York, 1985.

[8] K. Murata, Y. Fujii, N. Enomoto, M. Hata, T. Hoshino, M. Tsuda, Biophys. J. 2000,79, 982.

[9] H. Kandori, Biochim. Biophys. Acta 2000, 1460, 177.

[10] N. A. Dencher, H. J. Sass, G. Büldt, Biochim. Biophys. Acta 2000, 1460, 192.

[11] J. Wang, M. A. El-Sayed, Biophys. J. 2001, 80, 961.

[12] S. K. Pal, L. Zhao, A. H. Zewail, Proc. Nat. Ac. Sci. USA 2003, 100, 8113.

[13] S. Woutersen, U. Emmerichs, H. J. Bakker, Science 1997, 278, 658

[14] R. Laenen, C. Rauscher, A. Laubereau, Phys. Rev. Lett. 1998, 80, 2622.

[15] S. Woutersen, U. Emmerichs, H.-K. Nienhuys, H. J. Bakker, Phys. Rev. Lett. $1998,81,1106$.
[16] G. M. Gale, G. Gallot, F. Hache, N. Lascoux, S. Bratos, J.-C. Leicknam, Phys. Rev. Lett. 1999, 82, 1068.

[17] S. Woutersen, H. J. Bakker, Phys. Rev. Lett. 1999, 83, 2077.

[18] S. Woutersen, H. J. Bakker, Nature 1999, 402, 507.

[19] S. Bratos, G. M. Gale, G. Gallot, F. Hache, N. Lascoux, J.-C. Leicknam, Phys. Rev. E 2000, 61, 5211.

[20] H. Graener, G. Seifert, A. Laubereau, J. Chem. Phys. 1989, 91, 1043

[21] K. J. Gaffney, I. R. Piletic, M. D. Fayer, J. Phys. Chem. A 2002, 106, 9428.

[22] T. A. Ford, M. Falk, Can. J. Chem. 1968, 46, 3579.

[23] A. Szabo, J. Chem. Phys. 1984, 81, 150.

[24] H. J. Eichler, P. Günther, D. W. Pohl, Laser-Induced Dynamic Gratings, Springer, Berlin, 1986.

[25] H. J. Bakker, H.-K. Nienhuys, G. Gallot, N. Lascoux, G. M. Gale, J.-C. Leicknam, S. Bratos, J. Chem. Phys. 2002, 116, 2592.

[26] C. J. Fecko, J. D. Eaves, J. J. Loparo, A. Tokmako, P. L. Geissler, Science 2003, 301, 1698.

[27] J. B. Asbury, T. Steinel, C. Stromberg, S. A. Corcelli, C. P. Lawrence, J. L. Skinner, M. D. Fayer, J. Phys. Chem. A 2004, 108, 1107.

[28] H.-K. Nienhuys, R. A. van Santen, H. J. Bakker, J. Chem. Phys. 2000, 112, 8487.

[29] H. J. Bakker, S. Woutersen, H.-K. Nienhuys, Chem. Phys. 2000, 258, 233

[30] J. Deak, S. Rhea, L. Iwaki, D. D. Dlott, J. Phys. Chem. A 2000, 104, 4866.

[31] A. J. Lock, H. J. Bakker, J. Chem. Phys. 2002, 117, 1708-1713.

[32] A. Pakoulev, Z. Wang, D. D. Dlott, Chem. Phys. Lett. 2003, 371, 594.

[33] Z. Wang, A. Pakoulev, Y. Pang, D. D. Dlott, Chem. Phys. Lett. 2003, 378, 281.

[34] H.-K. Nienhuys, S. Woutersen, R. A. van Santen, H. J. Bakker, J. Chem. Phys. 1999, 111, 1494.

[35] W. B. Bosma, L. E. Fried, S. Mukamel, J. Chem. Phys. 1993, 98, 4413.

[36] A. Staib, J. T. Hynes, Chem. Phys. Lett. 1993, 204, 197.

Received: December 8, 2004

Published online on May 11, 2005 